\title{
The financial costs of a healthy eating weight-loss diet
}

\author{
S. Whybrow ${ }^{1}$, C. Pallister ${ }^{2}$, M. Gibbs ${ }^{1}$ and R. J. Stubbs ${ }^{2}$ \\ ${ }^{1}$ Food, Consumer Behaviour and Health Research Centre, Faculty of Health and Medical Sciences, University of Surrey, \\ Guildford GU2 7XH, UK and ${ }^{2}$ Slimming World, Alfreton DE55 4UE, UK
}

A 'healthy eating' diet of low-energy density is one of the most effective ways of achieving long-term weight-loss and weight-loss maintenance. Highly energy dense (processed) foods tend to be cheaper, in terms of energy per unit cost, and per serving, than foods that are of low-energy density, such as fruits and vegetables. Therefore, the apparent cost of selecting a low-energy density, and healthier, diet may be a barrier to long-term weight-loss. This study compared the food purchase costs of a commercial healthy eating weight-loss (HEWL) programme (Slimming World) to habitual diets consumed to approximate energy balance.

Adult women (117) completed weighed intake food diaries over $3 \mathrm{~d}$. Data from 188 women collected during three previous studies were used as representative of habitual diets ${ }^{(1-3)}$. Mean daily food purchase costs (p/d) and energy adjusted costs (p/MJ) were calculated from food prices collected during December 2009 and June 2010. Dietary energy density (ED), and weight, were calculated both including and excluding the contribution of drinks. BMR was estimated ${ }^{(4)}$. Differences between the two groups were compared using Student's $t$-tests.

\begin{tabular}{|c|c|c|c|c|c|}
\hline & \multicolumn{2}{|c|}{ Habitual $n 188$} & \multicolumn{2}{|c|}{ HEWL $n 117$} & \multirow[b]{2}{*}{$P$} \\
\hline & Mean & SD & Mean & SD & \\
\hline Age (years) & 41.4 & 12.1 & 45.6 & 13.0 & 0.005 \\
\hline Height (m) & 1.63 & 0.13 & 1.63 & 0.06 & NS \\
\hline Weight (kg) & 67.4 & 11.1 & 80.0 & 14.3 & $<0.001$ \\
\hline BMI $\left(\mathrm{kg} / \mathrm{m}^{2}\right)$ & 24.9 & 4.2 & 30.1 & 5.41 & $<0.001$ \\
\hline Energy intake $(\mathrm{MJ} / \mathrm{d})$ & 9.2 & 3.2 & 7.1 & 1.5 & $<0.001$ \\
\hline Ein:BMR & 1.58 & 0.56 & 1.13 & 0.26 & $<0.001$ \\
\hline Weight (F\&D) (g) & 3046 & 1175 & 3266 & 922 & 0.086 \\
\hline $\mathrm{ED}(\mathrm{F} \& \mathrm{D})(\mathrm{kJ} / 100 \mathrm{~g})$ & 348 & 158 & 235 & 65 & $<0.001$ \\
\hline Weight $(\mathrm{F})(\mathrm{g})$ & 1325 & 414 & 1428 & 419 & 0.037 \\
\hline ED (F) (kJ/100 g) & 655 & 186 & 488 & 122 & $<0.001$ \\
\hline Cost (p/day) & 553 & 212 & 590 & 189 & NS \\
\hline Cost (p/MJ) & 60.8 & 17.6 & 84.4 & 24.4 & $<0.001$ \\
\hline
\end{tabular}

ED, energy density. F\&D, including the contribution of foods and drinks. F, including the contribution of food only.

The HEWL diet was of lower ED than the habitual diet, whether calculated excluding or including the contribution of drinks. The energy adjusted cost of the HEWL diet was more expensive than the habitual diet. However, even though the HEWL group consumed more food (by weight) the higher cost per MJ was offset by lower energy intakes (as intended) and there was no significant difference between the mean daily costs of the two diets.

A healthy eating weight loss diet based on foods of a low energy density need not result in a higher purchase cost compared to habitual diets and can, as previously shown ${ }^{(5)}$, promote higher food intake by amount $(\mathrm{g})$ but lower energy intake.

Research relating to this article was part of the Diet, Obesity and Genes project (www.diogenes-eu.org) project funded by the European Commission (contract : Food-CT-2005-513946) in the Food Quality and Safety Priority of the Sixth Framework Program.

1. Whybrow S, Mayer C, Kirk TR et al. (2007) Obes Res 15, 673-85.

2. Stubbs RJ, O'Reilley L, Fuller Z et al. (2003) Food Standards Agency, London.

3. Whybrow S, Harrison CLS, Mayer C et al. (2006) Br J Nutr 95, 496-503.

4. Schofield WN (1985) Hum Nutr Clin Nutr 39, 5-41.

5. Ello-Martin JA, Roe LS, Ledikwe JH et al. (2007) Am J Clin Nutr, 85, 1465-1477. 